\title{
Analysis of vibration and temperature on the axle box bearing of a high-speed train
}

\author{
Zhiwei Wang ${ }^{1}$, Yao Cheng ${ }^{1}$, Paul Allen ${ }^{2}$, Zhonghui Yin ${ }^{1}$, Dong Zou ${ }^{1}$, Weihua Zhang ${ }^{1}$ \\ ${ }^{1}$ State Key Laboratory of Traction Power, Southwest Jiaotong University, Chengdu, Sichuan 610031, \\ China. \\ ${ }^{2}$ Institute of railway research, University of Huddersfield, Huddersfield, HD1 3DH, UK.
}

\begin{abstract}
A three-dimensional, vehicle-track coupled dynamics model has been developed that accurately reflects the dynamic performance of a high speed train during operation. The model includes novel elements that allow detailed consideration of the transmission system and axle box bearings. Within these novel elements a number of nonlinear factors have been modelled, including gear time-varying mesh stiffness, bearing stiffness, bearing clearance, and wheel-rail contact. The model has facilitated a detailed analysis of the vibration and temperature environment of the critical axle box bearing of high speed trains.

The proposed model was extensively validated by comparing the results of the simulation with those of experimental tests. The temperature characteristics of the axle box bearing of the motor car and the trailer were analyzed and the resultant mathematical model was subsequently validated through long-term experimental field tests. Additionally, the relationship between vibration and temperature was analyzed during operation. The results indicated that the loads acting on the axle box bearing closest to the gearbox of the motor car (bearing 1) are significantly higher than those distant to the gearbox (bearing 2), the cause being differences in structural stiffness, which also lead to higher local temperatures. Moreover, the roller-outer raceway contact force and temperature of Bearing 1 was also higher than that of bearing 2.

Conversely, when considering the trailer car, the dynamic performance and hence vibration and temperature environment of bearing 1 and bearing 2 were almost identical, this being a result of similarities in their structure and mounting arrangement.

In summary, the work demonstrates that the temperature and vibration characteristics of the axle box bearings and their assessment can be used to aid in the effective design and maintenance of high-speed trains, together with the development of remote condition based monitoring (RCM) systems.
\end{abstract}

Key words: High-speed train, vehicle-track coupled dynamics, axle box bearing, temperature, vibration

\section{Introduction}

The tapered roller bearing is a key component of high-speed trains and has a noticeable feature of high load capacity against axial and radial loads. However, the double-row tapered roller bearing (TRB) of the axle box is also one of the most vulnerable parts due to the load from the wheel-rail and bogie. Moreover, its dynamic performance directly affects the operational safety of high-speed trains and can even cause train derailment and serious accidents. The temperature and vibration of the axle box bearing can reflect its service state. As the temperature of the axle box bearing increases due to frictional heat at high rotational speed, its dynamic performance is likely to be affected [1] and vice versa [2]. Hence, increased temperature and vibration of the bearing are the critical parameters in axle boxes. Therefore, research into the dynamic and temperature characteristics of 
axle box bearings in high-speed trains is crucial in their design and optimum performance. In addition, the dynamic performance and temperature characteristics of the axle box bearing are useful for monitoring condition.

Previous investigations on bearing frictional torque and heat transfer characteristics mainly consisted of two basic methods, namely the global and local approaches. Thermal network and the finite-element method are the main methods in the analysis of bearing heat transfer. The thermal network is relatively easy and convenient compared to the finite-element method, as the actual structure is neglected. Finite-element methods are widely used in the study of temperature [3]. Based on classical theory, Kletzli [4] investigated the thermally induced failure of TRB in freight trains. Andoni [5] proposed a finite thermal model that was validated experimentally. The model can be used to obtain the temperature distribution, which is useful for identifying the ideal locations to place sensors for condition monitoring. Tarawneh $[2,6]$ developed a finite model for TRBs and conducted a series of experiments to analyze the heat transfer paths inside the TRB. It made a great progress in the understanding of overheating in bearings in the railway industry. The investigation indicated that internal heat generation and the increase in the local temperature of TRBs have a great influence on the bearing life and safety of operation in locomotives. Based on previous studies, Yan [1] developed the finite-element model for a real structure of double TRBs and conducted full-size rig tests to study the thermal characteristics. The investigations showed that the axial and radial loads directly affected the temperature of the whole TRB. Constant loads were adopted in the previous studies; however, the loads change dynamically during operation due to excitations from wheel-rail and bogie.

Fortunately, the dynamic performance of the TRB has been investigated widely in previous studies. Palmgren [7], Jones [8], and Harris [9] developed fundamental theories for the roller bearings. Based on a previous investigation, various studies have been conducted to understand the dynamic performance of TRBs, such as Andréason [10], Liu [11], and Houpert [12]. These studies mainly focus on load distributions, the effects of abnormal conditions, and the contact status of the TRBs. However, the coupling effects between the TRBs and the wheel set and bogie are not considered in the calculation. In addition, excitations in a vehicle system due to track irregularities are ignored. To study the wheel-rail excitations, many studies focused on the vehicle system dynamics, which examined the whole dynamics characteristics. Garg and Dukkipati [13] and Wickens [14] developed the classical vehicle dynamics theory, which focused only on the dynamic performance of the vehicle system. At increased running speed, Zhai et al. [15-17] thought that the influence of track structure should not be neglected and it was also validated experimentally. The similar concept has been adopted in many studies of railway dynamics[18-20]. Besides, the poor wheel conditions contribute to the enhancement of wheel-rail interactions and cause the vehicle-track components fatigue failure [21, 22]. Although many researchers focused on understanding railway vehicles and the dynamics performance of TRBs, the coupling effects between them are yet to be considered. Recently, Wang et al. [23] developed a new vehicle-track coupled dynamics model that considered the axle box bearing and studied the coupling effects on the vibration characteristics of the TRBs. The lifetime of the bearing is strongly influenced by the dynamic load environment [24,25], especially under intense wheel-rail excitation [26]. Therefore, the coupling effects between the axle box bearing and the vehicle-track systems should be considered when assessing its dynamics and temperature characteristics. In addition, the relationships between each aspect under investigation also need to be understood in order to better guide the condition monitoring, design and optimize. The main objective of this paper is to use the newly developed three-dimensional vehicle-track coupled dynamics model [23], to investigate the vibration characteristics of the axle box bearing in 
a high-speed train. Dynamic experimental tests are carried out to validate the model by comparing the results from experimental tests and simulations. Based on the vibration results obtained by simulation, the temperature characteristics of the axle box bearing are analyzed theoretically. Moreover, the relationship between the vibration and temperature of the axle box bearing during operation is analyzed. Finally, long-term field experimental tests were carried out to obtain the temperature characteristics of the axle box bearing during operation and to validate the theoretical results. Based on the dynamics model and the experimental results, the vibration and temperature characteristics of the axle box bearing of a high-speed train are discussed in detail.

\section{Vehicle-track coupled dynamics model}

The three-dimensional vehicle-track coupled dynamics model that considers the details of the axle box bearing and traction transmission system [23] is presented in this section. The new threedimensional vehicle-track coupled dynamics model is shown in Figure 1 and Figure 2. The traction transmission subsystem and the axle box subsystem are considered based on the classical vehicletrack model [17]. 
(a)
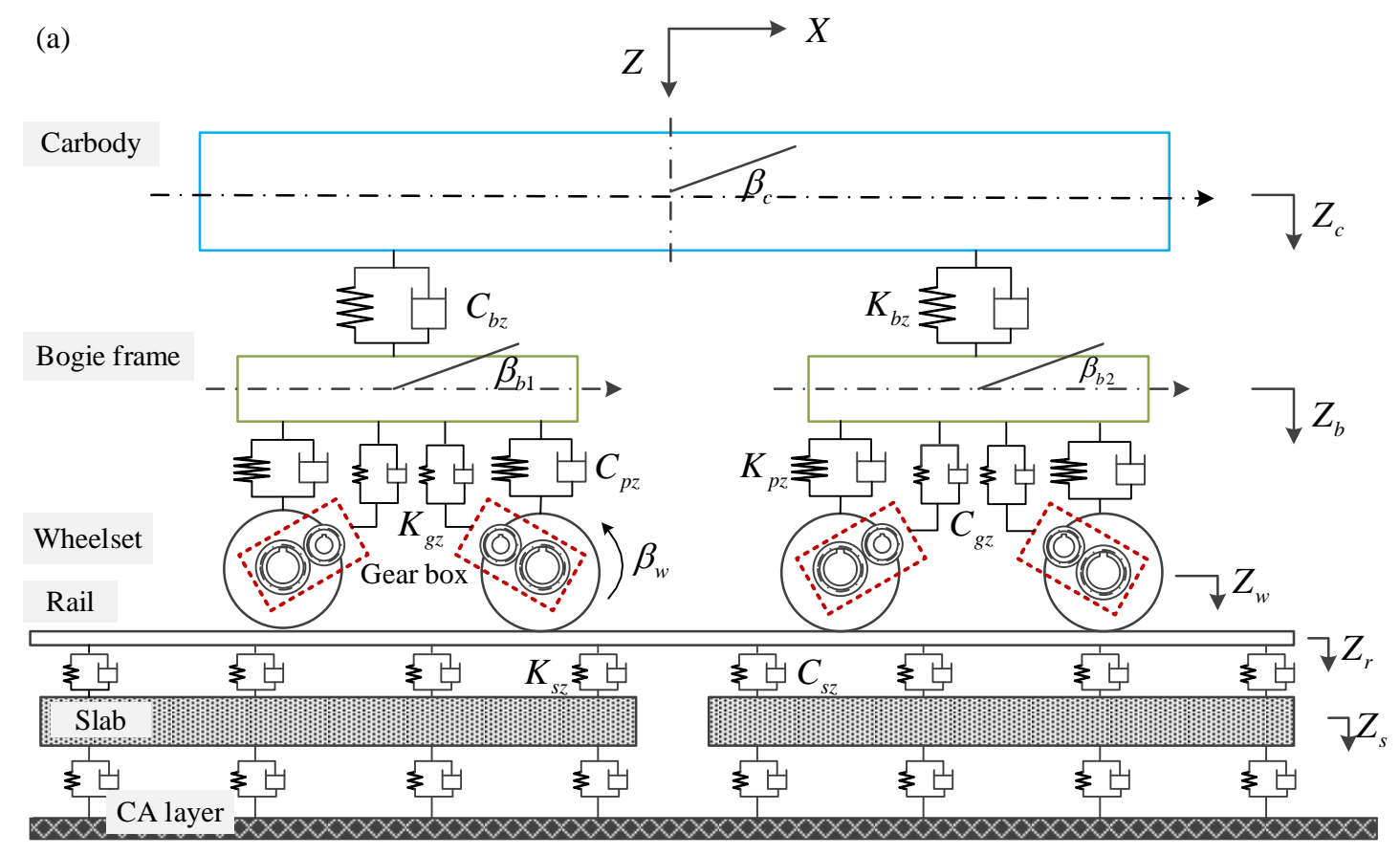

(b)

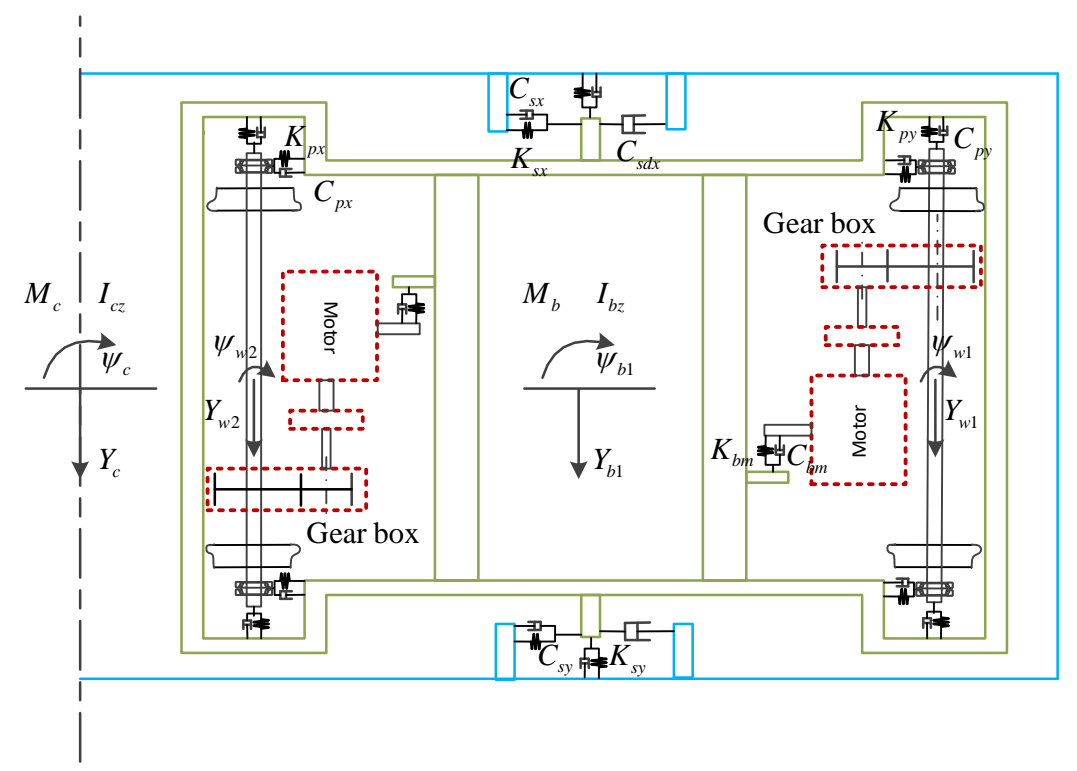

Figure 1. Motor car-track coupled dynamics model (a)elevation view and (b) planform. 


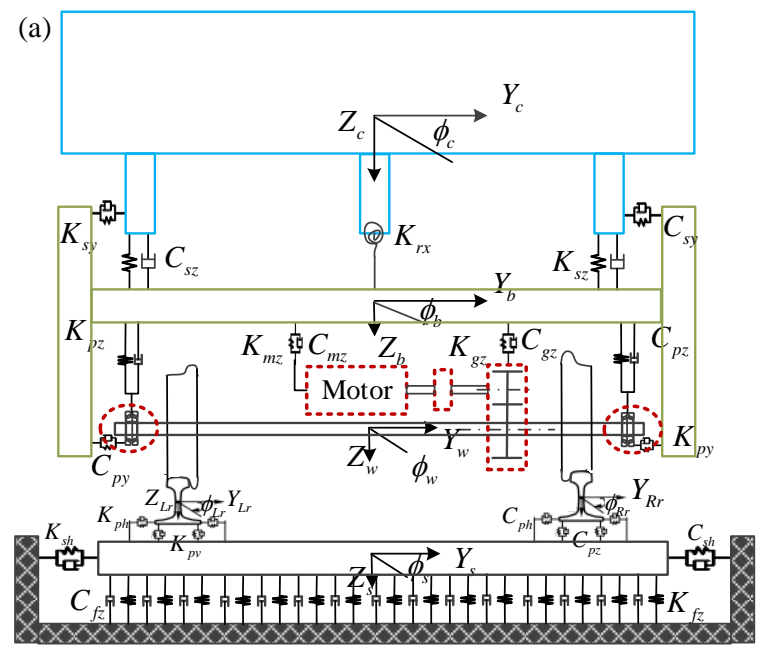

(b)
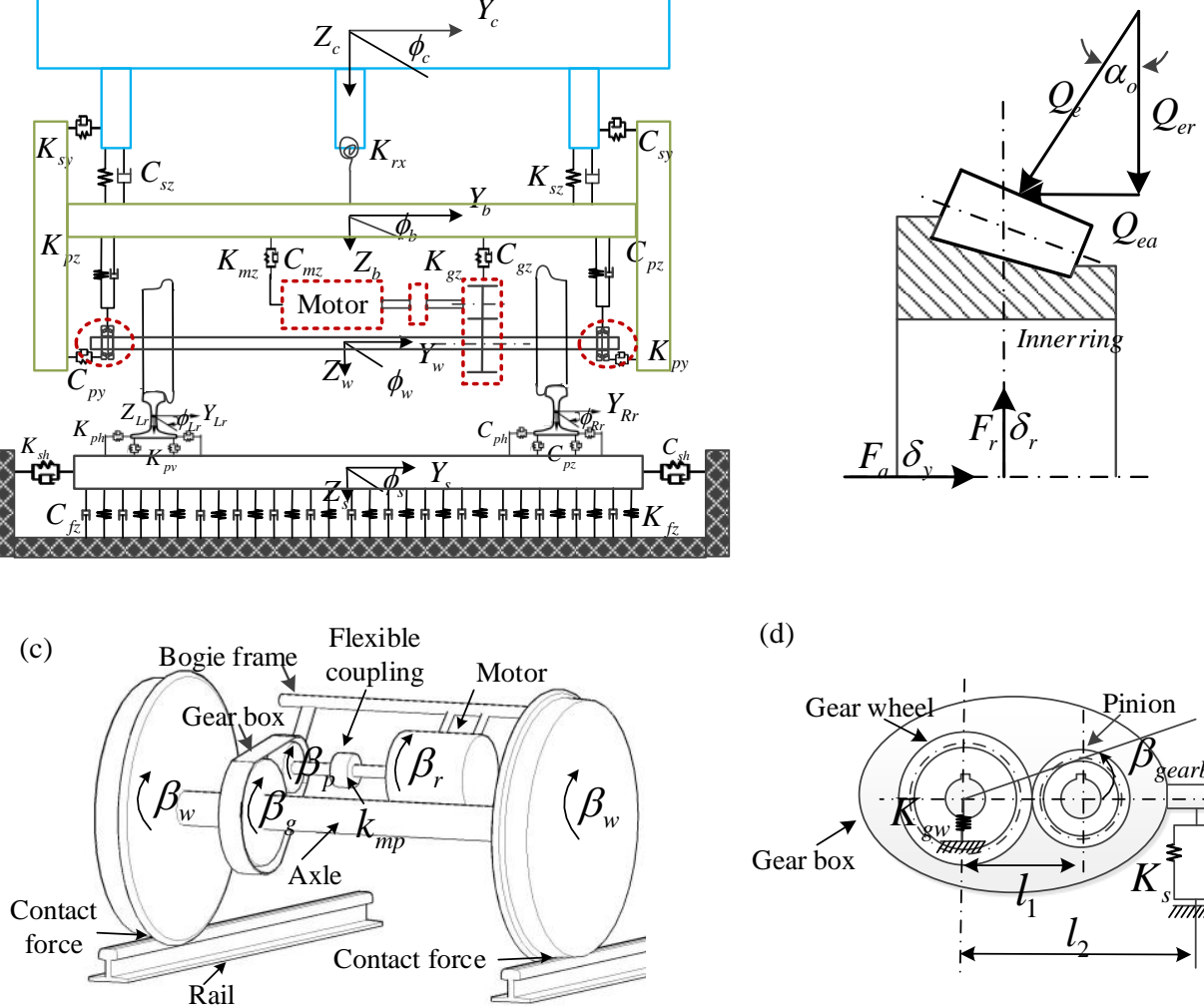

(d)

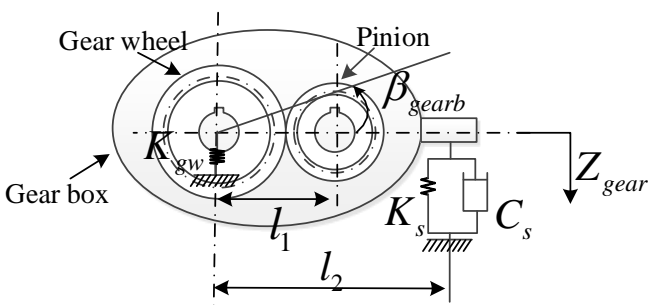

Figure 2. Motor car-track coupled dynamics model: (a) side view and (b) axle box bearing (c) traction transmission system and (d) gear box.

The dynamics model comprises four parts: the classical vehicle submodel, the classical track submodel, the new traction transmission system, and the axle box bearing submodel. The motor car model consists of a car body, two bogie frames, four traction transmission systems, four wheelsets, and eight axle boxes. All of the components are considered as rigid bodies. The car body is supported by two bogies via secondary suspensions at each end, and the bogie frames are connected to the wheelset via primary suspensions and axle boxes, as shown in Figure 1. The primary and secondary suspensions are modeled as parallel combinations of the equivalent linear springs and viscous dampers along the three translational directions. Yaw dampers and anti-roll springs were also included in the secondary suspension.

As seen in Figure 1 and Figure 2, the transmission system consisted of a traction motor, pinion, gear wheel, and gearbox housing. One end of the gearbox is connected to the bogie frame by an elastic support, and the other end to the wheelset axle; the pinion is located on the drive end of the gearbox, and the gearwheel is fixed to the wheelset axle, as shown in Figure 2 (c) and (d). During operation, the traction torque is transmitted to the pinion via an elastic coupling and then transmitted to the drive gear by meshing force to drive the vehicle. The axle box bearing used in high-speed trains employs a double row TRBs, which are subjected to wheel-rail excitation and also vehicle load. Details of the axle-bearing model are shown in Figure 2 (a) and (b), where the inner ring is fixed on the wheelset, and the outer ring is fixed on the axle box. In addition, the bearing clearance as well as the contact force between each roller and raceway is considered in detail.

The slab track submodel comprising rails and slab, as shown in Figure 1 (a) and Figure 2 (a). Both the left and the right rails are treated as Euler-Bernoulli beams with motions in the vertical, lateral, and torsional directions and are supported by slabs. The established three-dimensional slabs are described as elastic rectangular plates supported on a viscoelastic foundation. 
This model actually couples the torsional vibration of traction transmission systems with the traditional vehicle-track coupled dynamics model. The comprehensive vehicle dynamics model enables more realistic dynamic simulations under many conditions, such as the coupling effects between components during operation, traction, and braking. The motor car of high-speed train comprises 27 rigid bodies, and a maximum of five degrees of freedom (DOFs) are considered for each rigid body. As a result, there are 75 DOFs of the motor car submodel in total. The motion of each component and its corresponding nomenclature is shown in Table 1. More detailed information on the dynamics modeling, the gear mesh stiffness calculation, and the axle box submodel can be found in a previous report [23], and so these aspects are neglected here.

Table 1 DOFs of high-speed vehicle dynamics model.

\begin{tabular}{cccccc}
\hline Vehicle component & Lateral motion & Vertical motion & $\begin{array}{c}\text { Roll } \\
\text { motion }\end{array}$ & $\begin{array}{c}\text { Yaw } \\
\text { motion }\end{array}$ & $\begin{array}{c}\text { Pitch } \\
\text { motion }\end{array}$ \\
\hline $\begin{array}{c}\text { Car body } \\
\text { bogie frame (i }=1,\end{array}$ & $Y_{c}$ & $Z_{c}$ & $\phi_{c}$ & $\psi_{c}$ & $\beta_{c}$ \\
2) & $Y_{b i}$ & $Z_{b i}$ & $\phi_{b i}$ & $\psi_{b i}$ & $\beta_{b i}$ \\
motor (i = 1-4) & $Y_{m i}$ & $Z_{m i}$ & - & - & $\beta_{m i}$ \\
gear box (i = 1-4) & - & $Z_{m i}$ & - & - & $\beta_{g i}$ \\
pinion (i = 1-4) & - & - & - & - & $\beta_{p i}$ \\
axle box & $Y_{a i}$ & $Z_{a i}$ & - & - & - \\
(i = 1-8) & $Y_{w i}$ & $Z_{w i}$ & $\phi_{w i}$ & $\psi_{w i}$ & $\beta_{w i}$ \\
wheelset (i = 1-4)
\end{tabular}

\section{Wheel-rail interaction}

Wheel-rail interaction is the essential element coupling the vehicle subsystem and the track subsystem. The dynamic forces between wheel-rail interface are complex, which comprises the normal contact forces and the tangential creep forces. The nonlinear Hertzian elastic contact theory is applied to calculate the normal wheel-rail forces, which is described in [15-17]:

$$
P(t)= \begin{cases}{\left[\frac{1}{G} \delta Z(t)\right]^{3 / 2}} & , \delta Z(t)>0 \\ 0 & , \delta Z(t)<0\end{cases}
$$

where $P(t)$ is the normal wheel-rail force, $G$ is the constant of Hertzian wheel-rail contact, $\delta Z(t)$ is the wheel-rail normal elastic compression deformation at the contact point in the normal direction, which is given:

$$
\delta Z(t)=Z_{w}(t)-Z_{r}\left(x_{w}, t\right)-Z_{0}(t)
$$

where $Z_{w}(t)$ is the vertical displacement of wheelset, $Z_{r}\left(x_{w}, t\right)$ is the vertical displacement of rail corresponding to the wheelset and $Z_{0}(t)$ is the displacement of vertical track irregularities.

As for the wheel-rail creep forces, based on the Kalker's linear creep theory, the wheel-rail longitudinal creep force $F_{x}$, the lateral creep force $F_{y}$, and the spin creep torque $M_{z}$ can be described in [27]:

$$
\left\{\begin{array}{l}
F_{x}=-f_{11} \xi_{x} \\
F_{y}=-f_{22} \xi_{y}-f_{23} \xi_{s p} \\
M_{z}=f_{23} \xi_{y}-f_{33} \xi_{s p}
\end{array}\right.
$$

where the $f_{i j}$ is the creep coefficients and the $\xi_{x}, \xi_{y}$ and $\xi_{s p}$ are the longitudinal, lateral and spin creepage, respectively. Besides, the Shen-Hedrick-Elkins model [28] is used to make 
modification due to the Kalker's linear creep theory is limited in small creepages.

\section{Long-term experimental field tests for the axle box bearing of high- speed trains}

To validate the proposed dynamics model, experimental field tests were carried out on a high-speed railway line in China. The vibration data of the bogie frame and the axle box were obtained, and the vibration testing photograph and monitoring positions for the acquisition of the vibration data are shown in Figure 3. As shown in Figure 3(c) and (d), two accelerometers were mounted on the highspeed train motor car, one on the axle box and one on the bogie frame. The acceleration data were collected in the vertical direction at the sampling frequency of 1000 and $5000 \mathrm{~Hz}$ for bogie frame and gearbox, respectively.
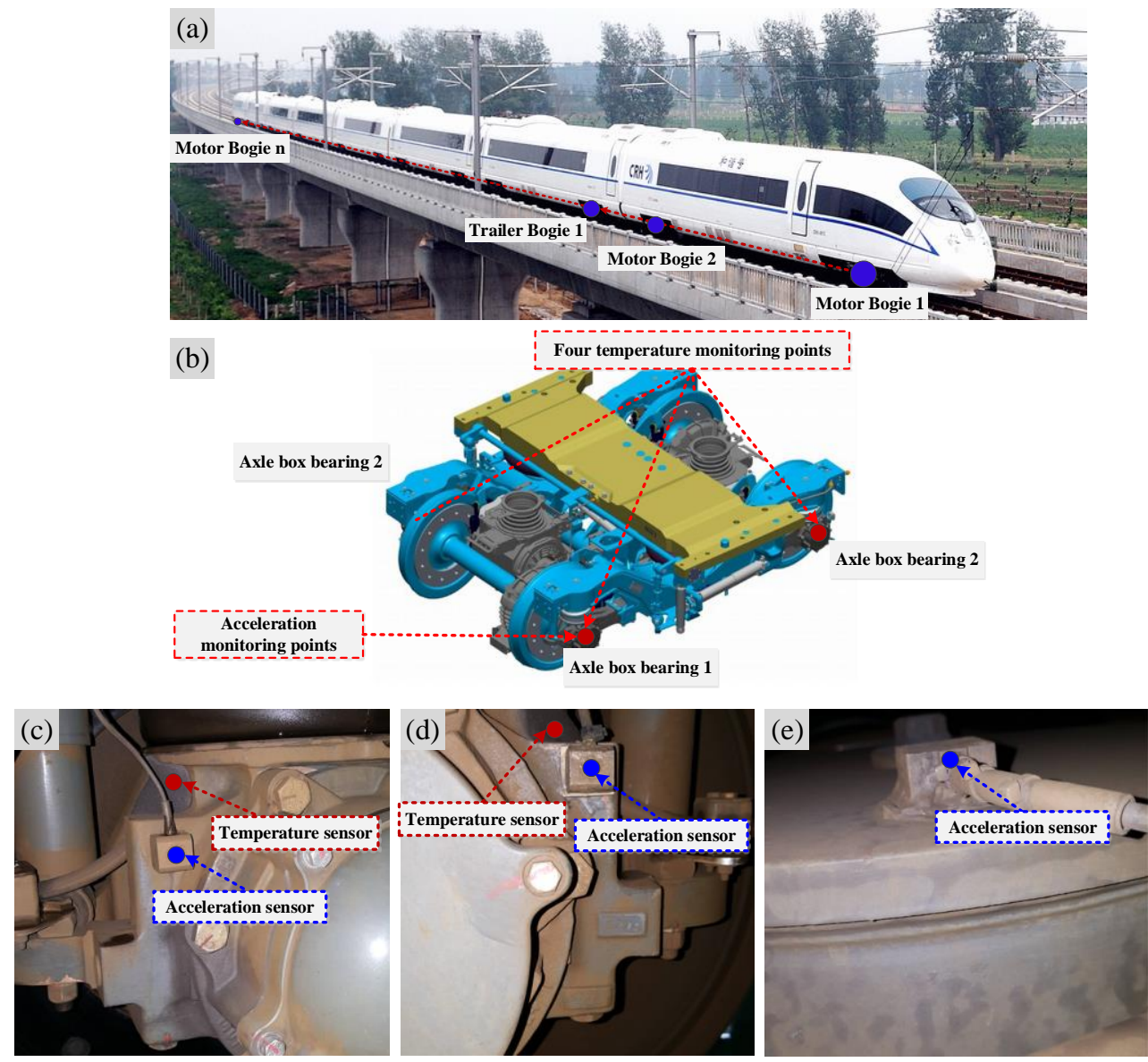

Figure 3. Field experimental tests: (a) A typical high-speed train; (b) three-dimensional model of a motor bogie; (c) location of acceleration and temperature sensors on the motor axle box bearing; and (d) location of the acceleration sensor on the bogie frame.

Moreover, the temperature data of the axle box bearings were acquired using a wireless transmission device system (WTDS), which is an online data-acquisition system of high-speed trains. The experimental tests require the sensors and the systems to work over a long period of time. Therefore reliability and anti-jamming are important concerns to obtain accurate temperature signals. The monitoring positions of the axle box bearing are shown in Figure 3. All of the axle box bearings of the motor cars and trailer cars were monitored by temperature sensors located at the same position; total 128 temperature sensors are used for one train: 64 sensors for motor car and 64 sensors for trailer. Figure 3(b) shows the three-dimensional model of a motor bogie. Four sensors were mounted on top of the axle box bearings and were utilized to collect the temperature signals of each motor axle box bearing in one motor 
bogie, as shown in Figure 3(c). As shown in Figure 3(b), the axle box bearing near the gearbox is labeled as axle box bearing 1 , and the one on the other side of the same wheelset is axle box bearing 2 . In the trailer car, the left axle box bearing is called bearing 1, and the other is called bearing 2 . It should be noted that these definitions of the axle box positions are used in the following discussion.

When a train operates online, WTDS collects the temperature signals from all of the axle box bearings every minute. Therefore, on a train with eight motor cars and eight trailer cars, 64 temperature values from all the motor and trailer axle box bearings are obtained every minute. For statistical significance, the temperature data from five typical high-speed trains equipped with axle box bearing sensors were acquired between August 11, 2016 and November 19, 2016.

\section{Analysis of the vibration characteristics for the axle box bearing}

Based on the established vehicle-track coupled dynamics model, the dynamic responses of the whole system including the vehicle, the axle box, the axle box bearing, and the track subsystems were obtained. The main parameters of the vehicle subsystems and the slab track used for the simulation were adopted from a previous study [23]. The parameters of axle box bearing are employed in the simulation as shown in Table 2. The numerical simulation results were compared with the field experimental test results, and the vibration characteristics of the axle box bearings were analyzed in this chapter.

Table 2 Structure parameters of axle box bearing of a high-speed train

\begin{tabular}{ll}
\hline Structure parameters & value \\
\hline The average diameter of roller $\left(D_{b} / \mathrm{mm}\right)$ & 23 \\
The contact angle of roller-inner raceway $\left(\alpha_{i} /\right.$ degree $)$ & 7.75 \\
The contact angle of roller-inner raceway $\left(\alpha_{e} /\right.$ degree $)$ & 10 \\
The effective length of roller $\left(l_{e} / \mathrm{mm}\right)$ & 45 \\
The pitch diameter of the bearing $\left(d_{m} / \mathrm{mm}\right)$ & 180.5 \\
Number of rollers in each row $(\mathrm{Z})$ & 21 \\
\hline
\end{tabular}

\subsection{Validation of the Dynamics model}

The simulations were performed using the proposed vehicle-track coupled dynamics model. In parallel, the corresponding vibration data was obtained from field experimental tests. The random track irregularity of a high-speed railway line comprising lateral and vertical irregularities is adopted in the numerical simulation, as shown in Figure 4. Comparing to the classical vehicle-track coupled dynamics model, the proposed model enables the simulation of the power transmission path from motor rotor to wheelset. During operation, the traction characteristics and the resistance characteristics of a typical high-speed train running on the Beijing-Shanghai high-speed railway line are obtained according to literature [29], as shown in Figure 5. The traction characteristics represent the maximum available force, which is an average characteristic of the same type high-speed trains from several high-speed lines. When the vehicle is running at constant speed, the equivalent traction torque of the motor is applied based on the resistance characteristics to maintain equilibrium. Hence, the traction torque acting on the motor rotor counteracts forces such as friction forces from wheel-rail interface, aerodynamic forces, and the dynamic forces from trailer car. 


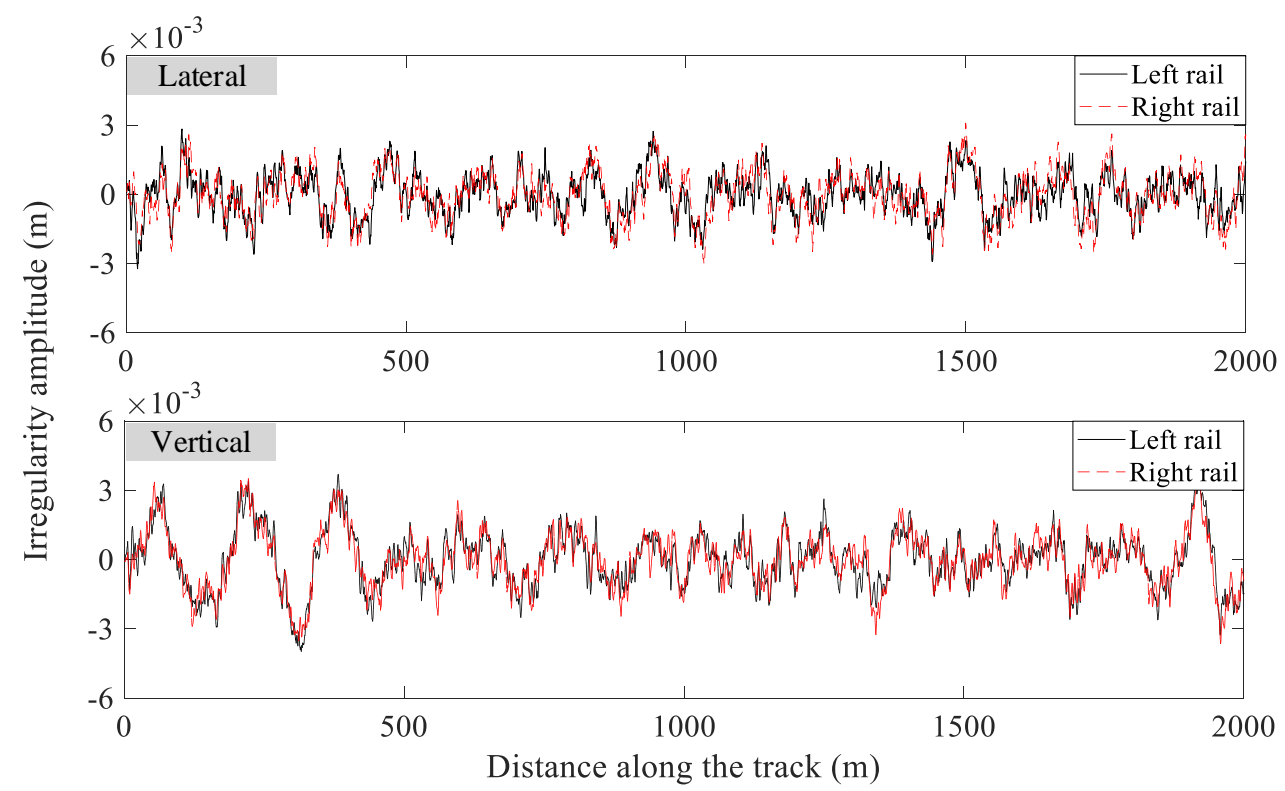

Figure 4 The random track irregularities of a high-speed railway line.

The truncated time histories of the vibration acceleration of the bogie frame and the axle box at a speed of $300 \mathrm{~km} / \mathrm{h}$ are shown in Figure 6 (a) and (b), respectively. As shown in Figure 6 (a), the simulated results for the bogie frame agree well with the experimental results in terms of both variation tendency and amplitude, and the maximum vibration acceleration amplitude was less than $10 \mathrm{~m} / \mathrm{s}^{2}$. In Figure 6 (b), the vibration levels of the axle box are higher than those of the bogie frame, and the maximum vibration acceleration amplitudes are close to $100 \mathrm{~m} / \mathrm{s}^{2}$. The calculated and experimental results show that the vibration from the axle box to the bogie frame can be effectively reduced by the primary suspension.

The root mean square (RMS) value is used to describe the fluctuation of the acceleration, and the RMS of the bogie frame acceleration is $1.6 \mathrm{~m} / \mathrm{s}^{2}$ and $1.5 \mathrm{~m} / \mathrm{s}^{2}$ for field tests and simulations. The RMS of the acceleration of axle box obtained by field tests and simulations is $8.8 \mathrm{~m} / \mathrm{s}^{2}$ and $7.6 \mathrm{~m} / \mathrm{s}^{2}$, respectively. It indicates that the RMS value of the bogie frame obtained by simulation is less than that of field tests with the error less than 7\%, while the RMS value of the axle box for simulation is less than that of field tests with the error of $15.6 \%$. These discrepancies may be due to the omission of the friction and flexible deformation of the components in the simulation. Although the absolute values from the simulated vibration acceleration in the model are lower than the experimental results, the RMS of vibration acceleration is basically consistent with each other.

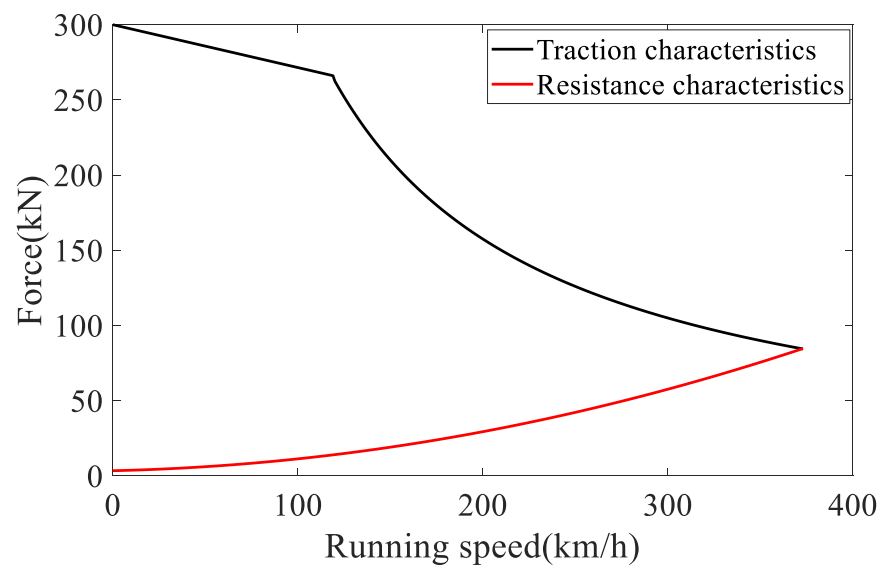

Figure 5 Traction and resistance characteristics curve of the high-speed train. 
(a)

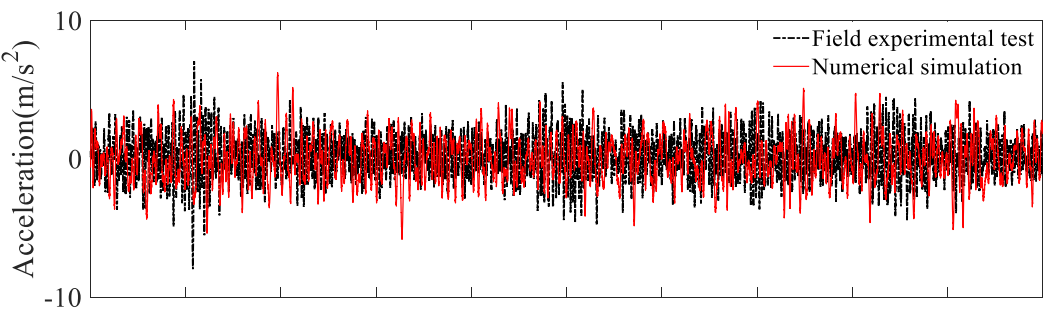

(b)

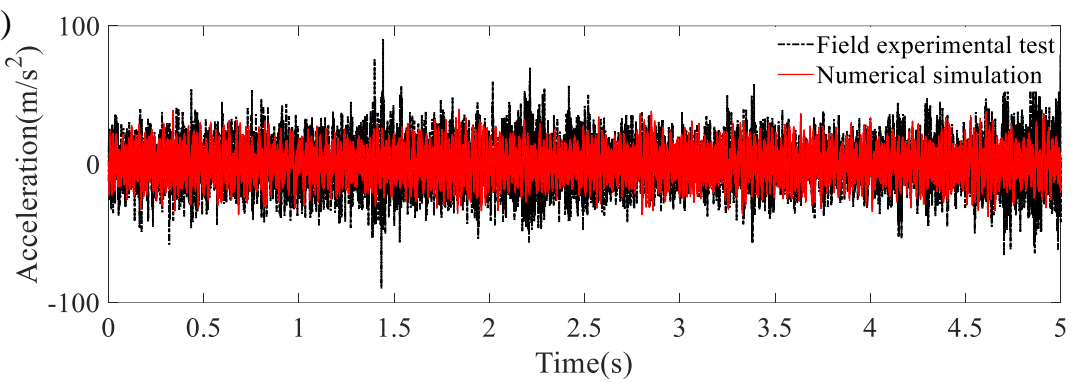

Figure 6. Time history of the vertical vibration acceleration of (a) the bogie frame and (b) axle box.

(a)

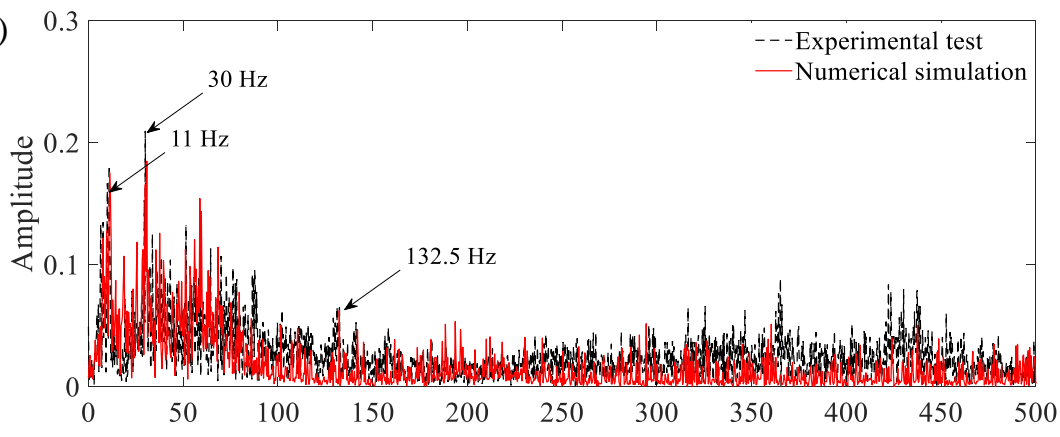

(b)

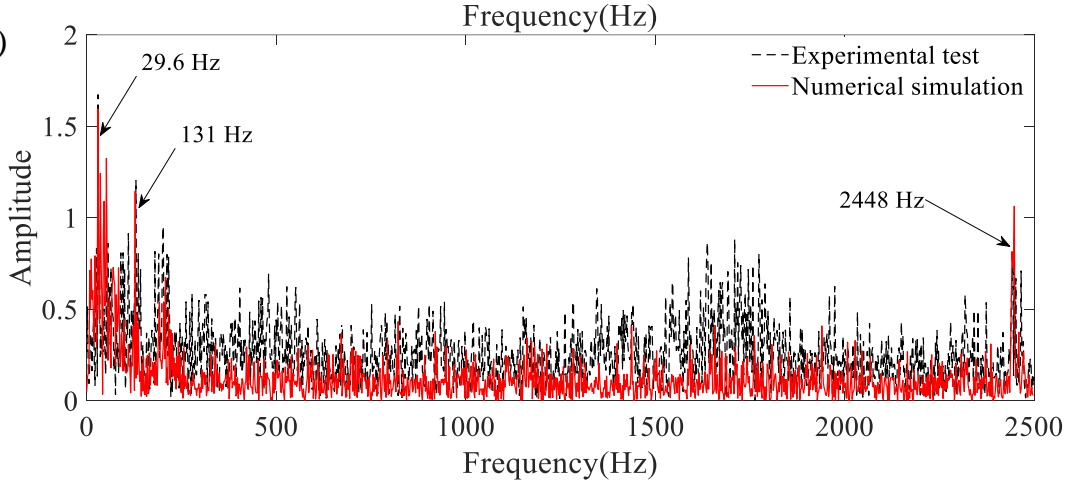

Figure 7 The frequency responses of vertical vibration acceleration of (a) the bogie frame and (b) axle box.

To further evaluate the proposed dynamics model, the vibration signals of the bogie frame and axle box obtained by simulations and tests are also compared in frequency domain, which are shown in Figure 7 (a) and (b), respectively. It can be seen form Figure 7 (a) that both the simulated and tested results of the bogie frame revel the frequency components of $11 \mathrm{~Hz}, 30 \mathrm{~Hz}$ and $132.5 \mathrm{~Hz}$. The frequency $11 \mathrm{~Hz}$ corresponds to the bounce eigen mode of the bogie frame, $30 \mathrm{~Hz}$ corresponds to the wheel rotate frequency, and $132.5 \mathrm{~Hz}$ corresponds to the sleeper excitation frequency. Excepts for the wheelset rotation frequency and the sleeper excitation frequency for axle box, the $2448 \mathrm{~Hz}$ corresponds to gear mesh frequency is also found in both of simulations and tests results, as shown in Figure 7 (b). Hence, the simulated results are basically consistent with the tested results in frequency domain. In general, the proposed vehicle-track coupled dynamics model is able to capture most of the vibration features of the system, thus supporting its validation. 


\subsection{The vibration characteristics of the axle box bearing during operation}

The main advantage of the dynamics model developed in this paper is its coupling with the traction transmission system and the axle box bearing. The vehicle vibration operation environment of axle box bearing is considered in the novel dynamics model. Thus, the vibration of track components and vehicle components induced by track irregularities, gear mesh, and traction torque can be performed using the proposed model. Hence, the dynamic loads acting on axle box bearing comprise of the static loads from vehicle and the dynamic loads induced by the excitations of traction torque, gear mesh and track irregularities. To understand the dynamic characteristics of the axle box bearing in detail, the three-dimensional vehicle-track coupling dynamics model was excited by: (a) only the traction transmission systems and (b) both the traction transmission systems and any track irregularities. Once again, the train ran in a straight line at a speed of $300 \mathrm{~km} / \mathrm{h}$. The results of the axle box bearing are shown in Figure 8 -Figure 10. Moreover, the dynamic response of the trailer car without the traction transmission system was also calculated under the same conditions and is shown in Figure 11 and Figure 12.

It should be noted that axle box bearing 1 is the one mounted on the axle near the end of the gearbox, and the axle box bearing 2 is located on the other side, as previously shown in Figure 3. According to previous research results [23], the resultant force of each axle box bearing is

$$
F_{\text {res }}=\sqrt{F_{\mathrm{a}}^{2}+F_{\mathrm{r}}^{2}}
$$

where $F_{\mathrm{a}}$ and $F_{\mathrm{r}}$ are the axial and radial forces of the axle box bearing, respectively. Furthermore, the axial and radial forces are given as

$$
\begin{gathered}
F_{\mathrm{a}}=\sum_{m=1}^{2} \sum_{j=1}^{21} Q_{m e j} \cos \alpha_{0} \cos \psi_{m j} \\
F_{\mathrm{r}}=\sum_{m=1}^{2} \sum_{j=1}^{21} Q_{m e j} \sin \alpha_{0}
\end{gathered}
$$

where $\alpha_{0}$ is the contact angle between the roller and the outer ring and $\psi_{m j}$ is the azimuthal location of $j$ th roller in the $m$ th column, $Q_{m e j}$ is the contact force between the jth roller in the mth column and raceway.

(a)

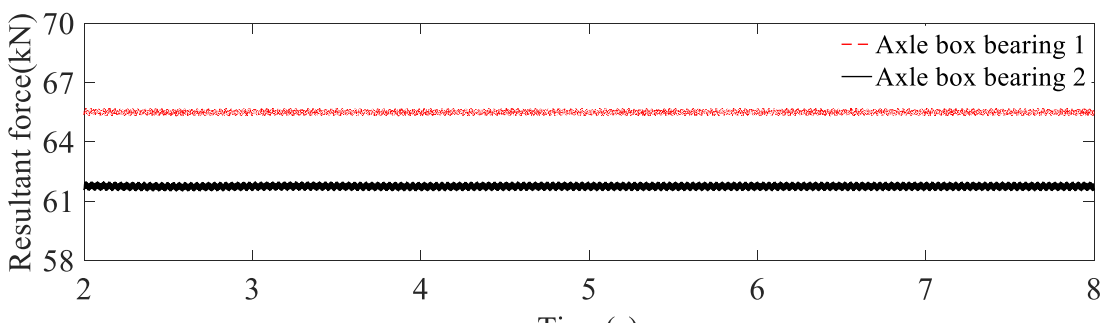

(b)

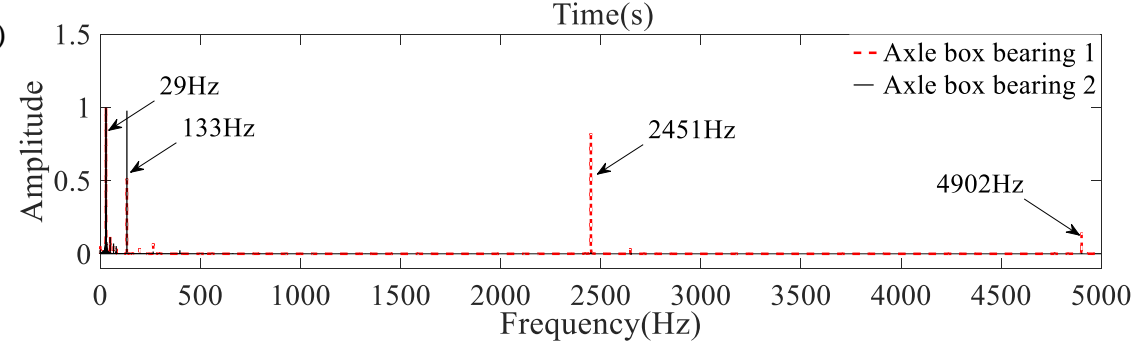

Figure 8. The results of the axle box bearing on a motor car: (a) the time history of the resultant force and (b) the corresponding spectrum results.

The dynamic forces in time domain and frequency domain only induced by traction transmission systems are shown in Figure 8. From Figure 8 (a), it can be seen that the dynamic resultant force 
$\left(F_{\text {res }}\right.$ ) of axle box bearing 2 is lower than that of bearing 1. Furthermore, the RMS of the dynamic force of axle box bearing 1 and bearing 2 are 65.5 and $61.7 \mathrm{kN}$, respectively. Figure 8(b) shows the frequency results based on the dynamic forces of the above axle box bearings. The main frequency components of the axle box bearing consist of the wheelset rotation frequency $29 \mathrm{~Hz}$ and the sleeper excitation frequency $133 \mathrm{~Hz}$. Moreover, there are two other main frequency components of bearing 1 including the meshing frequency of the gear pair, $2451 \mathrm{~Hz}$ and its double frequency, $4902 \mathrm{~Hz}$. Hence, it can be concluded that the difference in the dynamic forces between the two sets of axle box bearings is caused by the coupling effects of the suspension components and in particular the gear transmission system.

Figure 9 is the time history of the axle box bearing contact force $\left(Q_{\mathrm{e}}\right)$ between the roller and the outer raceway which is only excited by traction transmission systems. It indicates that the roller has both contact and noncontact regions during one cycle. A similar phenomenon occurs when the contact force of axle box bearing 1 is higher than that of bearing 2 , which means that the internal interaction of the axle box bearing 1 is more intense than that of bearing 2 .

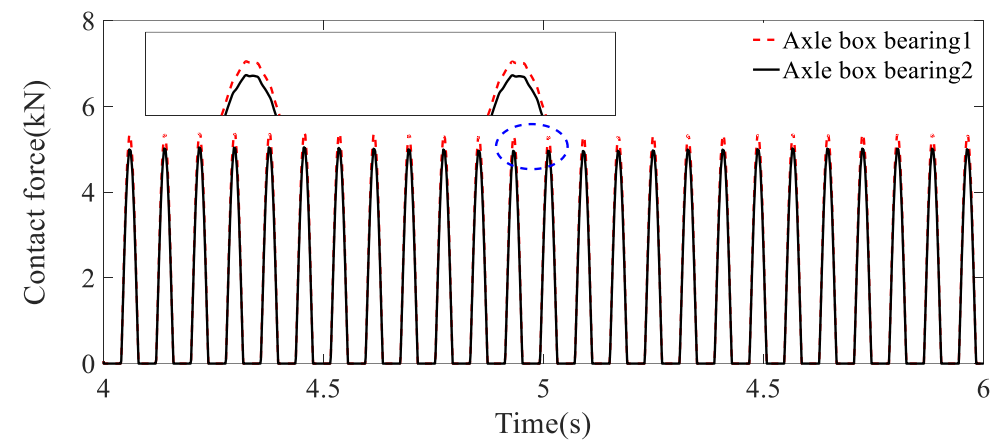

Figure 9. The time history of the roller-outer raceway contact force of the axle box bearing on the motor car.

(a)

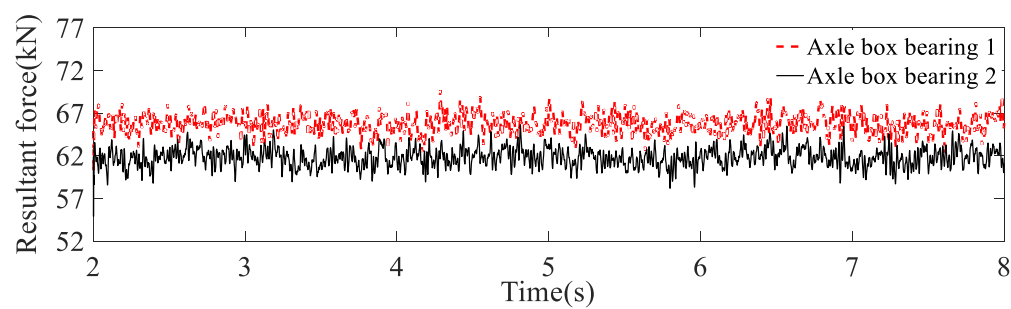

(b)

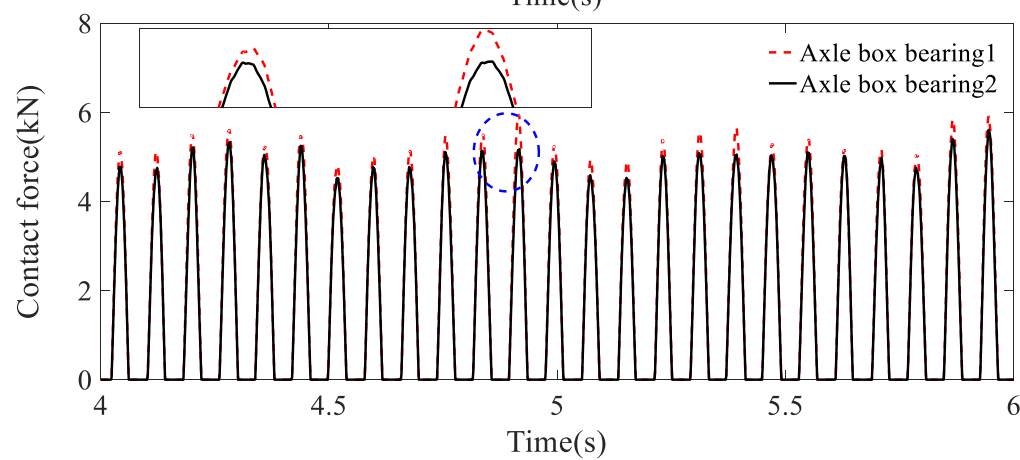

Figure 10. The results of the axle box bearing of the motor car: (a) the time history of the resultant force and (b) the roller-outer raceway contact force.

In Figure 10 (a), it can be clearly seen that the resultant force of both of the axle box bearings fluctuate violently in comparison to the results shown in Figure 8 (a), which was caused by the track irregularities. Additionally, the contact force between the roller and outer raceway of axle box bearing 1 is much higher than that with axle box bearing 2 under the excitation of track irregularities, 
as seen in Figure 10 (b). Furthermore, the RMS of the dynamic forces of axle box bearings 1 and 2 are 66.5 and $62.9 \mathrm{kN}$, respectively. It can be concluded that the operational environment of axle box bearing 1 is worse than that of bearing 2 , when both have been induced by the excitation conditions (a) and (b). During operation, the internal interactions of axle box bearing 1 of the motor car are higher compared to those of bearing 2 . The effects of wheel-rail excitation due to track irregularities on the axle box bearings are not negligible [23], and the dynamic differences existing between the two axle box bearings located at the two ends of the same axle are also critical to achieve an accurate evaluation and condition monitoring of an axle box bearing in a high-speed train.

(a)

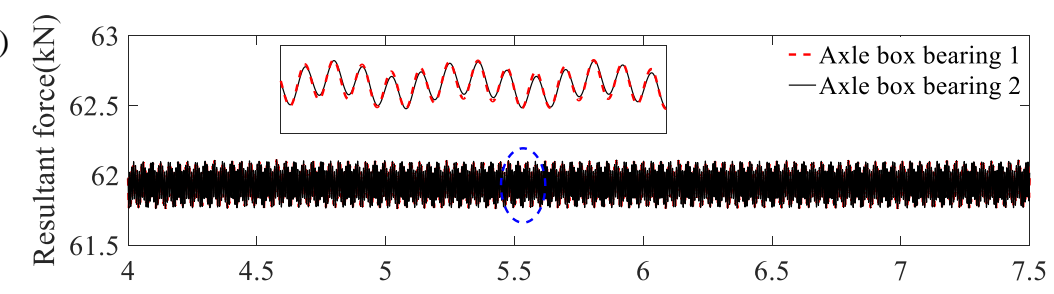

(b)

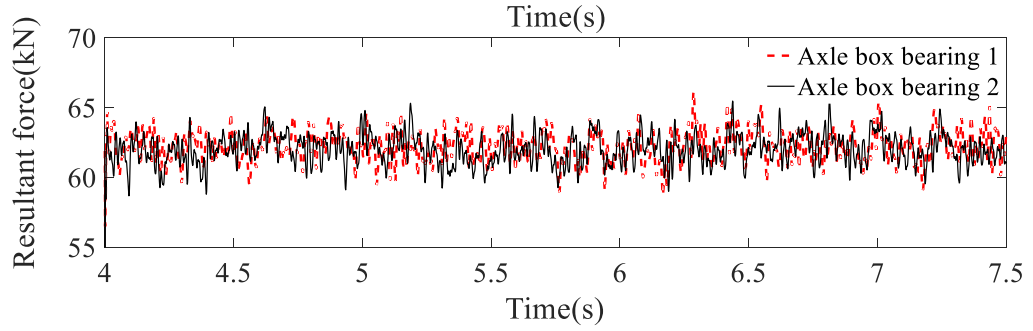

Figure 11. The results of the axle box bearing on the trailer car: (a) the time history of the resultant force without track irregularities and (b) with track irregularities.

(a)

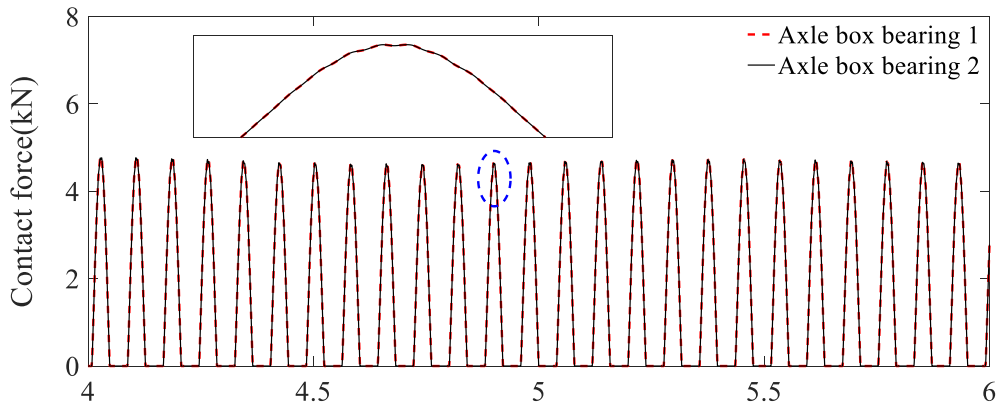

(b)

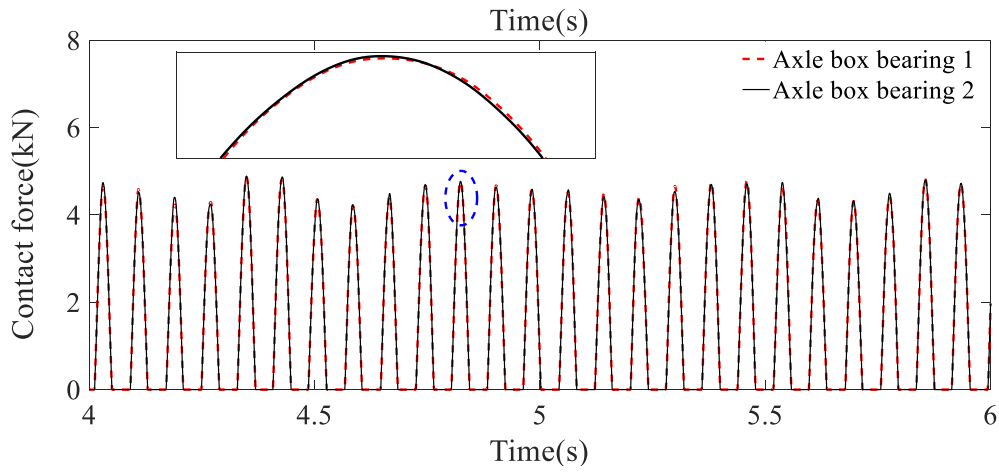

Figure 12. The roller-outer raceway contact force of the axle box bearing on the trailer car: (a) the time history of the resultant force without track irregularities and (b) with track irregularities.

Figure 11 shows the resultant force of the axle box bearing on the trailer car. From Figure 11 (a), it can be seen that the dynamic force of axle box bearing 1 (left side) agrees well with bearing 2 (right side), in terms of amplitude and variation tendency, which is due to the symmetrical machine structure. Additionally, there were almost no differences in the dynamics force between the two axle 
box bearings located on the same axle due to track irregularities. In addition, the amplitude of the dynamic force of the two bearings was basically the same.

Figure 12 shows the time history of the contact force between the roller and outer raceway. The dynamic contact force of the two axle box bearings is almost the same, no matter if they were excited by track irregularities or not. Therefore, the two axle box bearings, located on the left and right sides of the same axle, have almost the same dynamics performance during operation due to the structural properties and machine characteristics of the trailer car.

\section{Analysis of the temperature characteristics of the axle box bearing}

The dynamic and thermal stability of the axle box bearing is a key issue in high-speed trains. As the above studies on axle box bearing dynamics indicated, the interaction or the operation environment between bearing 1 and bearing 2 is quite different of motor car. The effects of the dynamic difference between the two axle box bearings from a thermal aspect and the temperature characteristics of the bearings were investigated using the theoretical and experimental methods outlined below.

\subsection{Theoretical analysis of the temperature characteristics of axle box bearing}

The overall temperature level of a TRB during operation depends on many variables, such as the applied load, operating speed, operational environment, and so on. Owing to the structural characteristics and mechanical principles, the operating conditions of the axle box bearings located on the two ends of the same axle, such as operation speed, operation environment, lubricant type, and rheological properties, can be considered to be consistent, whether they are located on the motor car or the trailer car. Therefore, the difference between the two bearings of the same wheelset is in the dynamic loads they experience during operation, and the effects of the applied load on the temperature of the bearings were therefore analyzed.

Bearing friction represents energy loss and heat generation. Frictional torque is critical to the bearing during operation as it directly affects the energy loss and the elevation in temperature. According to the literature [1], the power loss of a bearing can be calculated by Eq. (7). The impact of the bearing frictional torque is critical to the calculation of the bearing's power loss.

$$
P=M \cdot \omega=M \cdot \frac{2 \pi n}{60}
$$

In a previous study [30], the frictional torque comprises two components, as noted in Eq. (8).

$$
M=M_{0}+M_{1}+M_{2}
$$

where $M_{0}$ is the frictional torque relative to the bearing type, rotation speed, and the lubrication property; $M_{1}$ is the frictional torque caused by the radial force and $M_{2}$ is the frictional force due to the axial force.

$$
M_{0}=\left\{\begin{array}{lc}
160 \times 10^{-7} f_{0} D_{\mathrm{m}}^{3} & v n<2000, \\
10^{-7} f_{0}(v n)^{2 / 3} D_{\mathrm{m}}^{3} & v n \geq 2000,
\end{array}\right.
$$

where $D_{\mathrm{m}}$ is the average diameter, $f_{0}$ and $f_{1}$ are constants relative to the lubrication conditions, $v$ is the kinematic viscosity and $n$ is the rotation speed of the bearing.

$$
M_{1}=2 f_{1} Y F_{\mathrm{r}} D_{\mathrm{m}}
$$

where $f_{1}$ is a constant depending on the type of condition, $Y$ is a constant, and $F_{\mathrm{r}}$ is the radial force.

$$
M_{2}=f_{2} F_{\mathrm{a}} D_{\mathrm{m}}
$$


where $f_{2}$ is a constant and $F_{a}$ is the axial force. The above proportionality equations establish the power loss relationship depending on the load, speed, and lubrication conditions. Hence, by combining Eqs. (7)-(11), it was found that

$$
P \propto\left(F_{\mathrm{r}}, F_{\mathrm{a}}\right)
$$

It can be concluded that the loads on the bearing directly contribute to the increase in power loss. The axle box bearings of the motor car or trailer car have almost the same conditions, such as lubrication conditions, rotation speed, temperature, heat dissipation conditions, etc. Therefore, it can be inferred that the higher load on an axle box bearing contributes to a higher power loss and a higher temperature during the operation of a high-speed train. Furthermore, in the motor car, the temperature of the axle box bearing located near the gear box is higher than that of the bearing farther away due to the dynamic difference between the two bearings as noted in the above analysis. However, for a trailer car, the temperature of the two axle box bearings mounted on the same axle should be the same.

\subsection{The temperature characteristics of an axle box bearing during operation}

This chapter, provides a general description of temperature of axle box bearing. Because there was a large volume of test data, Figure 13 shows only part of the axle box bearing temperature time history for a motor car and trailer car, that is, for about 35 days. It can be seen that the bearing temperature of both the motor car and the trailer car decreases with decreasing ambient temperature. The temperature on the motor car is higher than that of the trailer car, which is due to structural differences. The maximum amplitude of the bearing temperature for the motor car and the trailer car were $82^{\circ} \mathrm{C}$ and $69.8^{\circ} \mathrm{C}$, respectively.
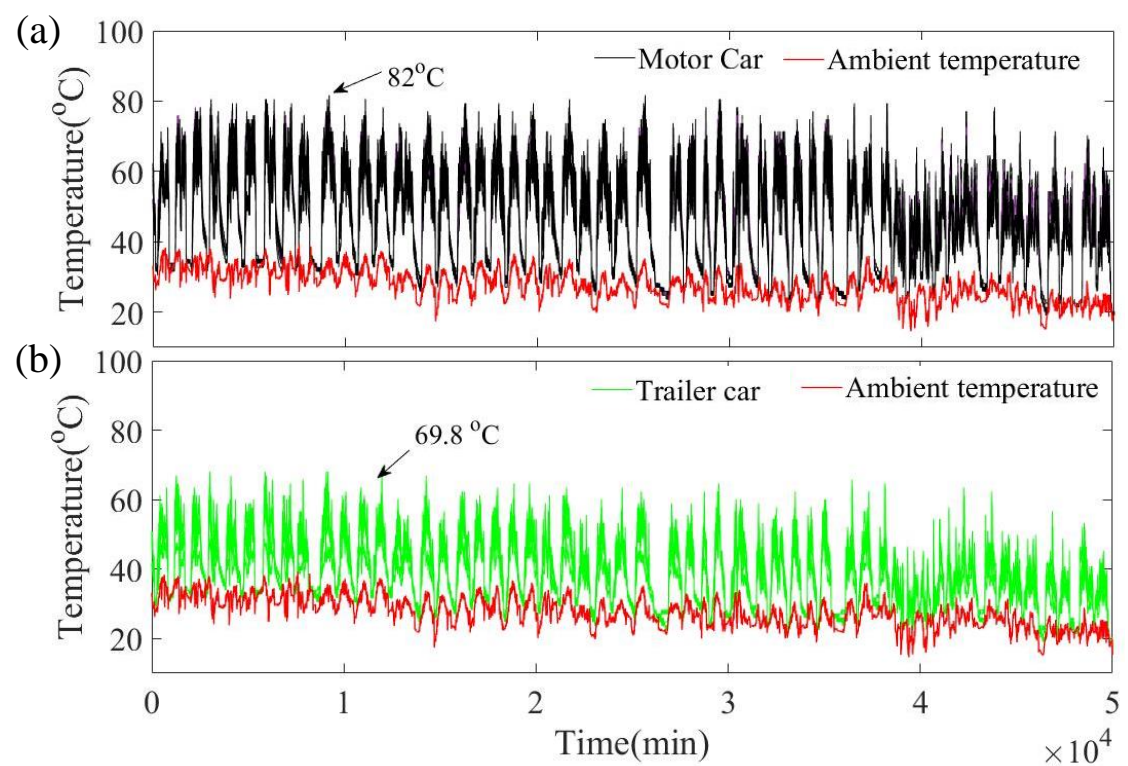

Figure 13. The temperature time history of axle box bearing for the motor car (a) and the trailer car (b).

Figure 14 is an enlarged view of a section taken from Figure 13 that shows the variation in the axle box bearing temperature of the motor car and trailer car over one day. The black dotted line represents the temperature of the bearing in the motor car, the green solid line represents the temperature of the bearing in the trailer car, and the blue solid line represents the ambient temperature (the temperature scale is shown on the left axis). The red dotted line represents the running speed, which is shown on the right axis. The high-speed train in China may run at different 
speeds at different times, but mainly runs at 300 and $200 \mathrm{~km} / \mathrm{h}$, as shown in Figure 14 . The axle box temperature rises with operation time and then stabilizes. Certainly, it can be seen that the axle box bearing temperature of the motor car is basically higher than that of the trailer car. However, the difference in vehicle and bearing states sometimes cause the axle box bearing temperature of trailer car to be higher than that of motor car. When the running speed is $300 \mathrm{~km} / \mathrm{h}$, the axle box bearing temperature of both the motor and trailer cars is relatively higher than the temperature when the running speed is $200 \mathrm{~km} / \mathrm{h}$.

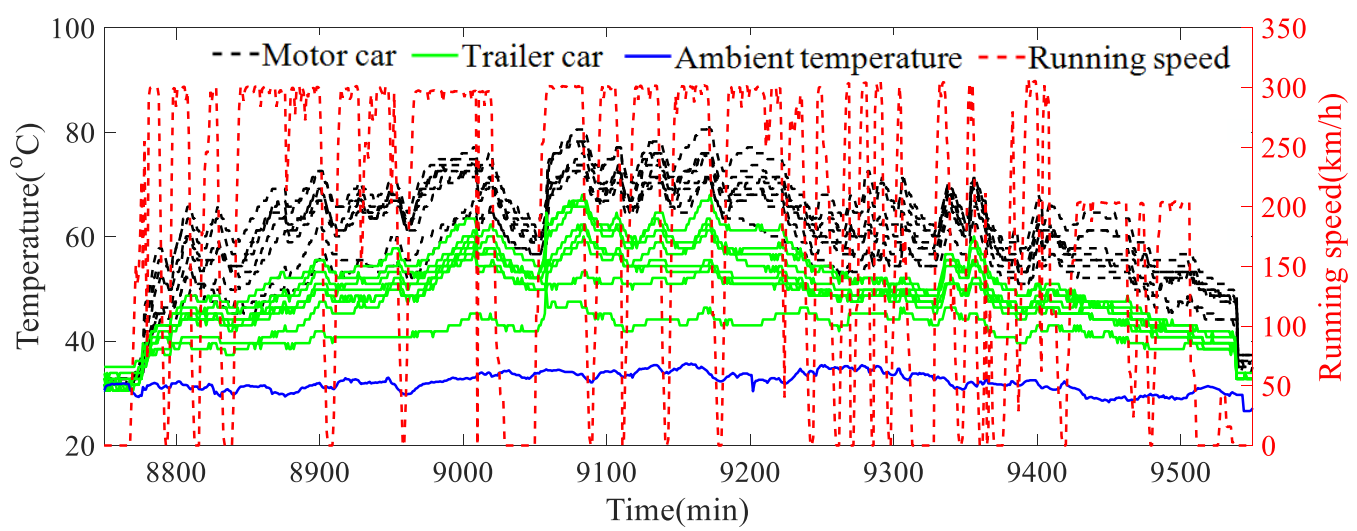

Figure 14. Partial enlargement of the temperature time history of axle box bearing for the motor and trailer cars.

\section{Discussions}

To analyze the temperature rises of axle box bearing during operation, its distributions between different bearings on the same vehicle and between different vehicles are investigated further. Moreover, the temperature distribution of the bearings located on the same wheelset are discussed in terms of the statistical indicators, which is also explained from the view of dynamics, as started below.

\subsection{The temperature between different bearings and different vehicles}

The axle box bearing temperature is acquired when the train runs at its commercial operating speed of $300 \mathrm{~km} / \mathrm{h}$. The mean value of the acquired temperature is used to assess the differences between axle box bearing. Due to similarity in the temperatures across bearings of the same vehicle, only one motor car and one trailer car bearing temperature data set is illustrated in Figure 15 and Figure 16, respectively. Ws represents wheel set, and the number 1 to 4 is the subscript of the wheelset, $\mathrm{Ab}$ represents the axle box bearing, and the number 1 and 2 is the subscript of the bearing as mentioned above.

Figure 15 shows the mean value of the two axle box bearings located on the wheelset of the same vehicle at different days. It can be seen that the temperature of axle box bearing 1 and 2 located on different wheelset has the similar tendency with respected to the time. Besides, the mean value of the temperature of axle box bearing 1 is basically higher than that of the axle box bearing 2 . And the mean value of bearing temperature fluctuates with different days, which is mainly caused by the time difference of the vehicle running with it commercial operation speed.

Unlike the motor car, the temperature difference of two axle box bearings located on the same wheelset is negligible, as shown in Figure 16. Moreover, fluctuation tendency of the different bearings of the same vehicle is almost the same due to the similar operation environment. However, there also exits some difference between the different bearings located on different 
wheelset, which could be caused by many factors, such as the wheel conditions and the lubrication conditions.

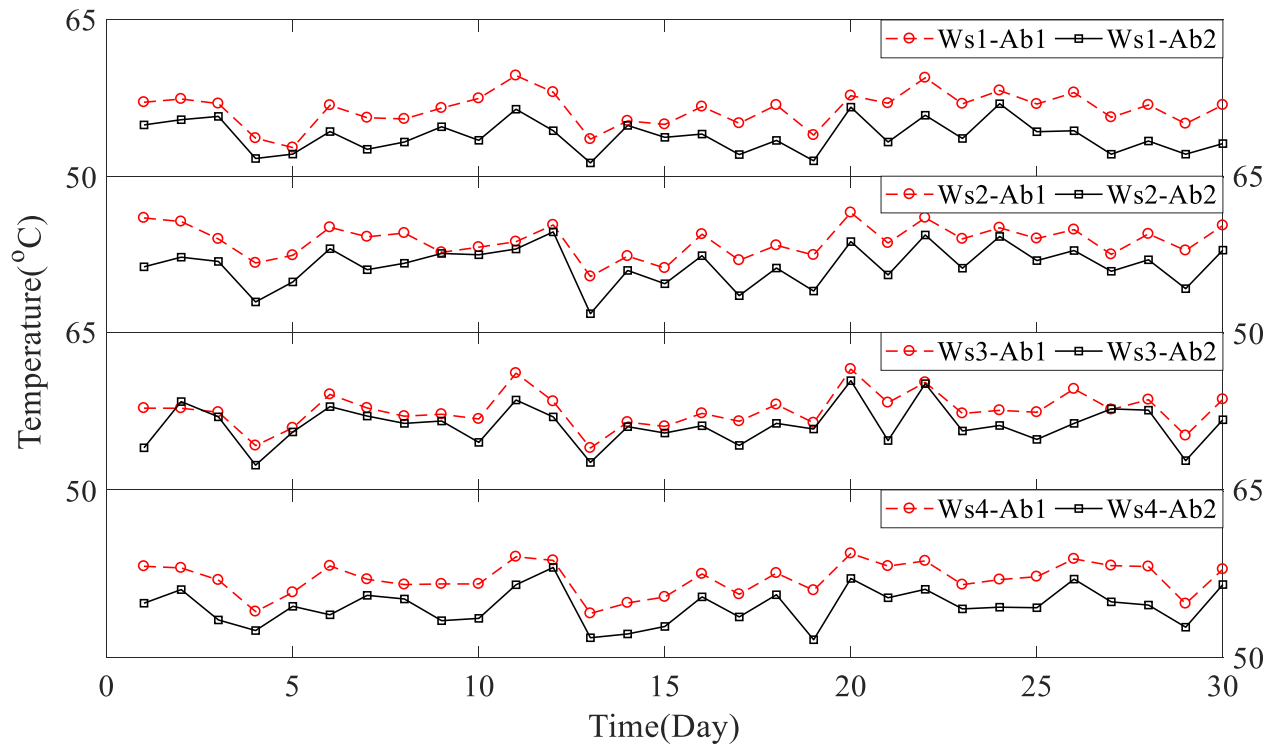

Figure 15 The average temperature of different axle box bearing of the motor car.

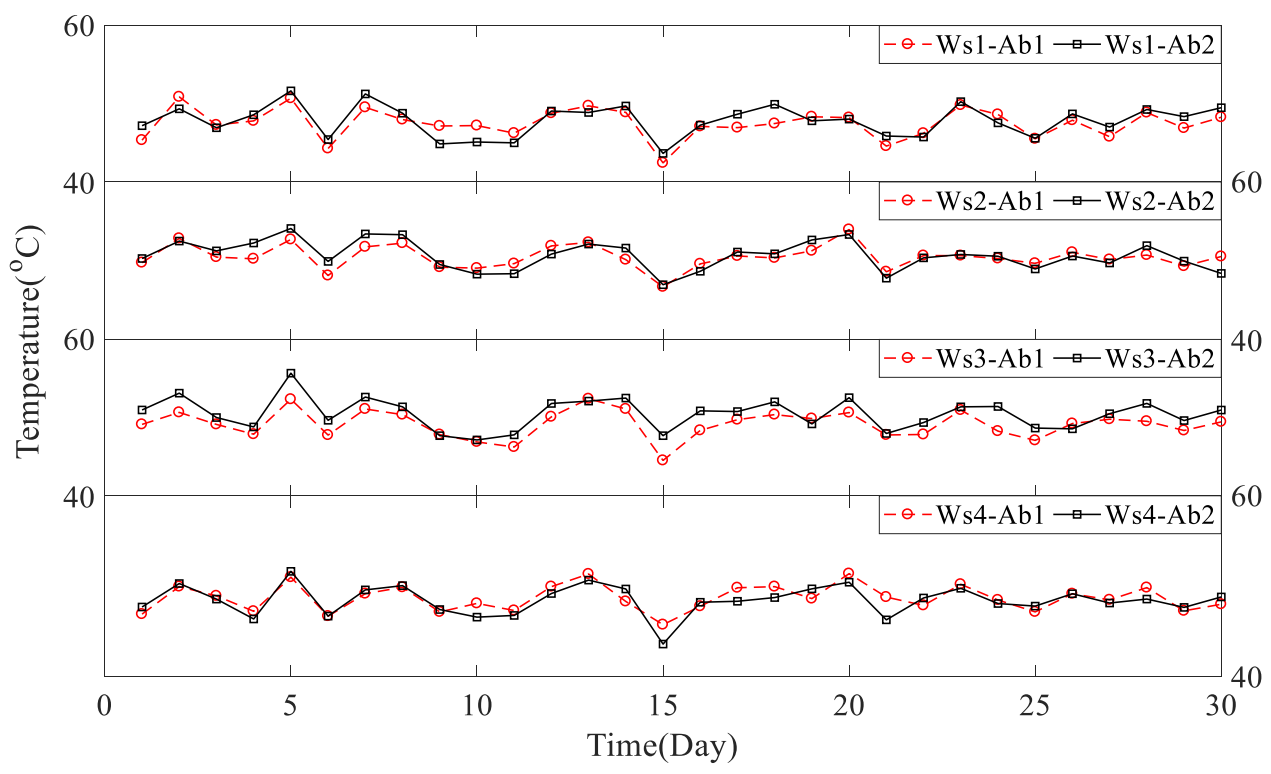

Figure 16 The average temperature of different axle box bearing of the trailer car.

To investigate the temperature distribution between different vehicles and to compare the difference in the temperature of bearing 1 and bearing 2 of the same wheelset, the average values of the bearings of five high-speed trains were recorded at a speed of $300 \mathrm{~km} / \mathrm{h}$, as shown in Figure 17. Each car contains eight axle box bearings; four bearings mounted on the positions of bearing 1 and bearing 2 each. The average temperature of bearing 1 or 2 for each car was calculated from the four bearings at each position. Figure 17 (a) shows the results from the motor car, which concludes that the temperature of bearing 1 is higher than that of bearing 2 due to differences in dynamic interaction. For the trailer car, the temperature characteristics of axle box bearings 1 and 2 are basically the same, due to the symmetrical structure. However, some difference of axle box bearings 1 and 2 for trailers may also be caused by the vehicle states (wheel states and lubrication state). Therefore, the temperature characteristics of the motor car and the trailer car are consistent with the previous theoretical analysis. 
It can be also seen from Figure 17 (a) and (b) that the temperature mean values of axle box bearing are different between different vehicles. This phenomenon is mainly caused by the different vehicle states, such as different suspensions parameters, wheel conditions and the lubrication conditions, changed during its operation.

(a)

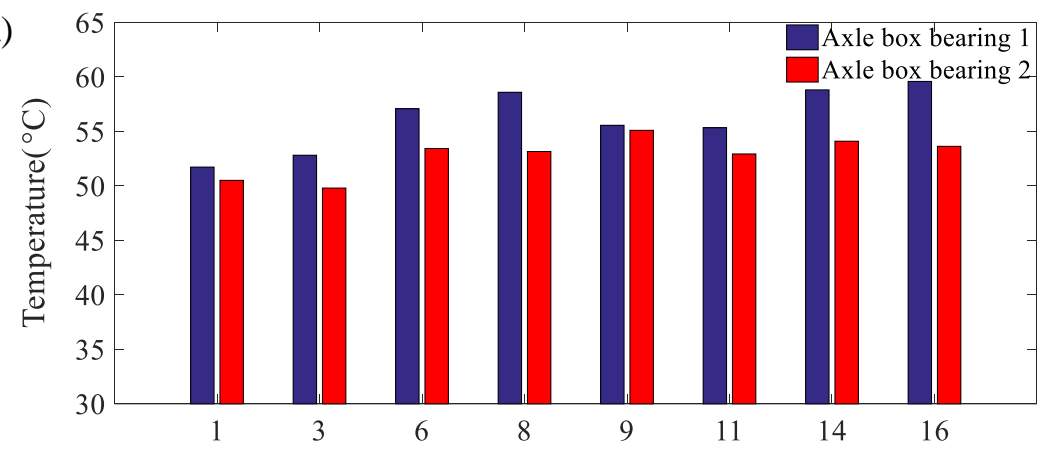

(b)

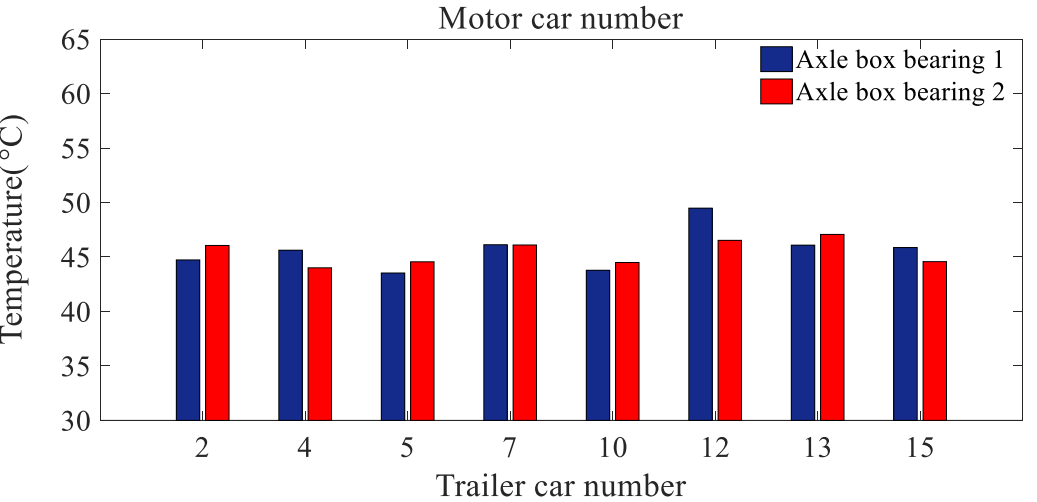

Figure 17. The average value of the axle box temperature of different cars at a speed of $300 \mathrm{~km} / \mathrm{h}$ :

(a) motor cars and (b) trailers.

\subsection{The analysis of temperature and dynamic forces between axle box 1 and}

\section{2.}

According to the above analysis, it can be concluded that the temperature of axle box bearing 1 of the motor car is much higher than that of axle box 2 due to higher loads. However, there is virtually no difference in the temperature between axle box 1 and 2 of the trailer car, which is consistent with the theoretical analysis. The high-speed train investigated in this study ran at speeds of 200 and $300 \mathrm{~km} / \mathrm{h}$. For a detailed analysis, the dynamic responses of the axle box bearings in the vehicletrack coupling system were calculated at different speeds. The temperature characteristics were also obtained at speeds of 200 and $300 \mathrm{~km} / \mathrm{h}$.

Figure 18 shows the roller-outer raceway contact force of the axle box bearing of the motor car and trailer car at speeds of 200 and $300 \mathrm{~km} / \mathrm{h}$. It can be seen that the roller-outer raceway contact force of bearing 1 of the motor car was higher than the one on bearing 2, by $13.5 \%$ and $10.5 \%$ for speeds of 200 and $300 \mathrm{~km} / \mathrm{h}$, respectively. However, the contact force of bearings 1 and 2 of the trailer car is almost the same at both speeds. The maximum contact forces of bearings 1 and 2 of the motor car and the trailer car increase when the running speed changes from 200 to $300 \mathrm{~km} / \mathrm{h}$.

Figure 19 shows the statistical results of the bearing temperature at speeds of 200 and $300 \mathrm{~km} / \mathrm{h}$. The triangles and circles are the temperature average values at each speed, respectively. Again the temperature of bearing 1 is higher than that of bearing 2 for the motor car at both speeds. Furthermore, the temperature difference is larger between the two bearings as the dynamic interaction becomes more severe in the high speed range. The temperature characteristics of 
bearings 1 and 2 of the trailer are almost the same, as shown in Figure 19(c) and (d).
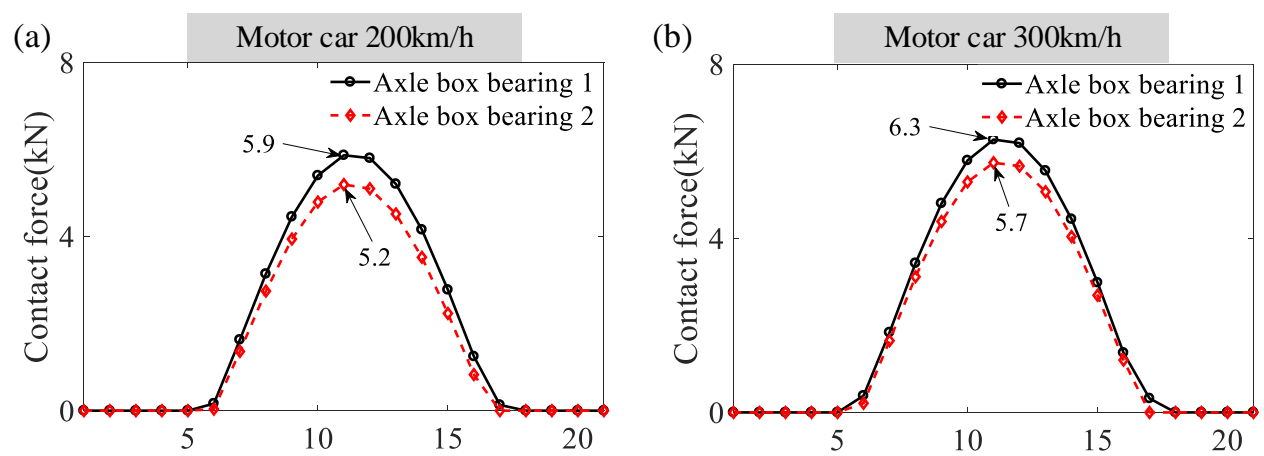

The position number of rollers

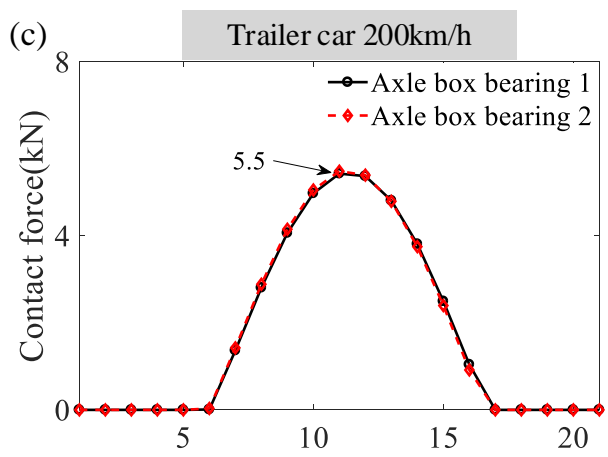

The position number of rollers

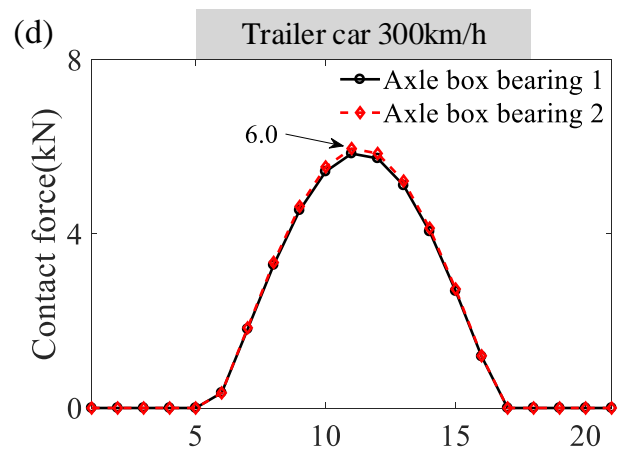

The position number of rollers

The position number of rollers

Figure 18. The roller-outer raceway contact force of the axle box bearings at different speeds.

(a)

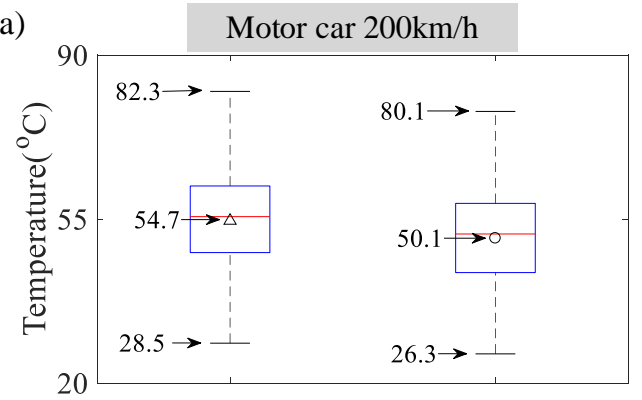

(c)

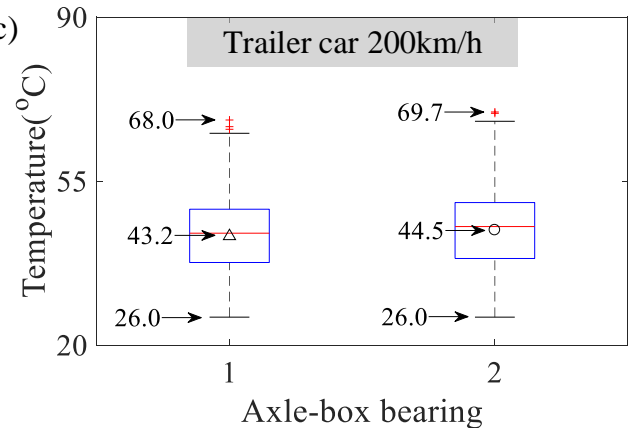

(b)

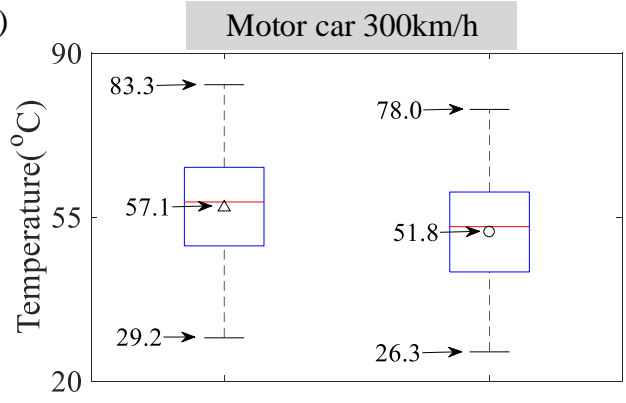

(d)

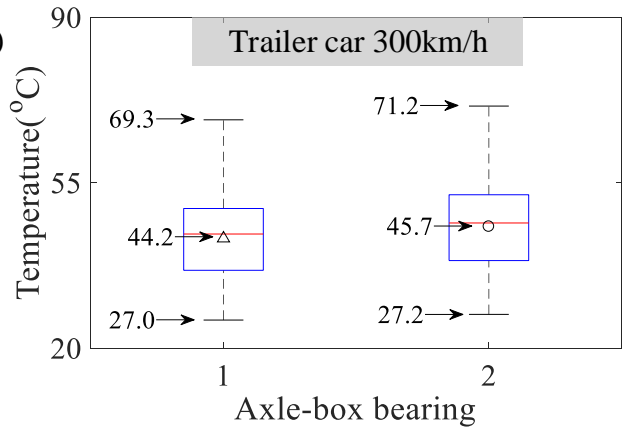

Figure 19. The results of the axle box bearing temperature at different speeds $(-5 \%, 25 \%, 50 \%$, $75 \%, 95 \%$ percentiles).

\section{Conclusions}

The established vehicle-track coupled dynamics model includes the dynamic effects from the traction transmission system and the axle box bearing. Thus, the dynamic performance of the axle box bearing can be simulated under the coupled system to represent the operating situation more closely. The time-varying mesh stiffness, nonlinear wheel-rail interactions, bearing stiffness, and 
clearances are considered in this model. The model was validated by comparing the results of simulations and experimental tests. Furthermore, the temperature characteristics of the bearing were theoretically analyzed based on the dynamic performance of the bearing, which is supported by long-term field temperature tests.

The calculated results indicate that the dynamic forces that act on bearing 1 are higher than those on bearing 2 owing to the structural differences of the motor car, which is reflected in the temperature. However, there is almost no difference in the dynamic loads acting on bearings 1 and 2 of the trailer car. And theoretically the temperature characteristics between the two bearings should also be very similar, which was validated by experimental tests. Moreover, the axle box bearing temperature of the motor car was generally higher than that of the trailer car.

Additionally, the flexible deformation of the vehicle components, such as the axle box, wheelset, and bogie frame, could influence the dynamic interaction of the axle box bearings. However, the proposed dynamics model only considers the vehicle as a rigid body, which could be improved in the future. The longitudinal motions of the vehicle system are not considered in the paper, which will be investigated in our future studies. Besides, several factors contribute to the temperature rise of the axle box bearing, such as the rotational vibration, operation time, and wheelset state, which should also be considered further in the future. Moreover, the axle box bearing's model could be improved to analyze the internal temperature characteristics of the bearing under coupling environments in future studies, which is very helpful in vehicle design, development of condition monitoring and maintenance.

\section{Acknowledgments}

The first author thanks the support of the China Scholarship Council.

\section{Funding}

The author(s) is grateful for the financial support provided by the National Key Research and Development Program of China (No 2016YFB1200401) and the Fundamental Research Funds for the Central Universities (No 2682018CX71).

\section{References}

1 Yan, K., Wang N., Zhai, Q., et al., Theoretical and experimental investigation on the thermal characteristics of double-row tapered roller bearings of high speed locomotive, Int. J. Heat Mass Transfer. 2015; 84: 1119-1130.

2 Tarawneh, C.M., Cole, K.D., Wilson, B.M., et al., Experimental and models for the thermal response of railroad tapered-roller bearings, Int. J. Heat Mass Transfer. 2008; 51 (25-26): 5794 5803.

3 Yu, Y.T., Du, P.G., Wang, Z.W., Research on the current application status of finite element method, J. Mach. Des. 2005; 22 (3): 6-9.

4 Kletzli, D.B., Cusano, C., Conry, T.F., Thermally-induced failures in railroad tapered roller bearings, Tribol. Trans. 1999; 42 (4): 824-832.

5 Andoni, Z., Arturo, F., Tarawneh, C.M., et al., Experimentally validated finite element analysis of railroad bearing adapter operating temperature, in: ASME 2012 International Mechanical Engineering Congress and Exposition, 2012; 7: 9-15.

6 Tarawneh, C.M., Arturo, A.F., Javier, A.K., et al., Thermal modeling of a railroad tapered-roller 
bearing using finite element analysis, J. Therm. Sci. Eng. Appl. 2012; 4 (3).

7 Palmgren, A. Ball and Roller Bearing Engineering. Philadelphia: SKF Industries Inc.; 1959.

8 Jones, A.B. A general theory for elastically constrained ball and radial roller bearings under arbitrary load and speed conditions. J Basic Eng. 1960; 82: 309-320.

9 Harris, T.A., Rolling Bearing Analysis. 2nd ed. New York: John Wiley \&Sons; 1984.

10 Andréason, S. Load distribution in a taper roller bearing arrangement considering misalignment. Tribology. 1973; 6 (3): 84-92.

11 Liu, J.Y. Analysis of tapered roller bearings considering high speed and combined loading. J Lubrication Tech. 1976; 98 (4): 564-572.

12 Houpert, L. An enhanced study of the load-displacement relationships for rolling element bearings. J Tribol. 2013; 136 (1): 011105-011116.

13 Garg, V.K., Dukkipati, R.V. Dynamics of railway vehicle systems. Toronto: Academic Press; 1984.

14 Wickens, A.H. Fundamentals of rail vehicle dynamics: guidance and stability. Lisse: Swets \& Zeitlinger; 2003.

15 Zhai, W.M., Sun, X. A detailed model for investigating vertical interaction between railway vehicle and track. Veh Syst Dyn. 1994; 23 (1) :603-615.

16 Zhai, W, Cai Z. Dynamic interaction between a lumpedmass vehicle and a discretely supported continuous rail track. Comput Struct. 1997; 63 (5):987-997.

17 Zhai, W.M., Wang, K.Y., Cai, C.B. Fundamentals of vehicle-track coupled dynamics. Veh Syst Dyn. 2009; 47 (11): 1349-1376.

18 Diana G, Cheli F, Bruni S, et al. Interaction between railroad superstructure and railway vehicles. Veh Syst Dyn. 1994; 23(Suppl): 75-86.

19 Nielsen JCO, Igeland A. Vertical dynamic interaction between train and track - influence of wheel and track imperfections. J Sound Vib. 1995;187(5):825-839.

20 Chaar N, Berg M. Simulation of vehicle-track interaction with flexible wheelsets, moving track models and field tests. Veh Syst Dyn. 2007; 44(sup1): 921-931.

21 Wang ZW, Mei GM, Zhang WH, et al. Effects of polygonal wear of wheels on the dynamic performance of the gearbox housing of a high-speed train. Proc IMechE, Part F: J Rail and Rapid Transit 2018. 232(6): 1852-1863.

22 Wang ZW, Cheng Y, Mei GM, et al. Torsional vibration analysis of the gear transmission system of high-speed trains with wheel defects. Proc IMechE, Part F: J Rail and Rapid Transit 2019 DOI: 10.1177/0954409719833791.

23 Wang, Z.W., Zhang, W.H., Yin, Z.H., et al., Effect of vehicle vibration environment of highspeed train on dynamic performance of axle box bearing, Veh Syst Dyn 2019; 57(4): 543-563.

24 Williams, S., Ahlbeck, D., Harrison, H., Railroad bearing performance under the wheel impact load environment. In ASME Winter Annual Meeting.1987, Boston, Massachusetts, USA: American Society of Mechanical Engineers (Paper) (ASME, New York, NY, USA) pap 87-WA/RT-1, p. 7.

25 Kumagai, N., Ishikawa, H., Haga, K., et al., Factors of wheel flats occurrence and preventive measures. Wear. 1990;144 (1): 277-287.

26 Barke, D.W., Chiu, W.K., A review of the effects of out-of-round wheels on track and vehicle components, Proceedings of the Institution of Mechanical Engineers, Part F: Journal of Rail and Rapid Transit. 2015; 219 (3): 151-175.

27 Zai WM, Xia H, Cai CB, et al., High-speed train-track-bridge dynamic interactions - Part I: theoretical model and numerical simulation, Int J Rail Transp. 2013;1(1-2):3-24.

28 Shen ZY, Hedrick JK, Elkins JA. A comparison of alternative creep force models for rail vehicle 
dynamic analysis. Veh Syst Dyn. 1983;12(1-3):79-83.

29 Zhang WH. Dynamics of coupled systems in high-speed trains: theory and practice. Beijing: Science Press; 2013.

30 SKF General Catalogue, 1981. 